\title{
LAMP3 (CD208) Expression in Squamous Cell Carcinoma and Epithelial Dysplasia of the Oral Cavity and Clinicopathological Characteristics of Unfavorable Prognosis
}

\author{
Mehdi Shahabinejad ${ }^{1}$, Reza Zare ${ }^{2}$, Zeynab Asadi ${ }^{3}$, Farnaz Mohajertehran*1,2
}

\begin{abstract}
Background: This study aimed to evaluate LAMP3 (CD208) gene expression in oral squamous cell carcinoma (OSCC) and dysplastic oral epithelium by quantitative real-time polymerase chain reaction (qPCR) and compare LAMP3 expression in different disease grades and stages.

Methods: In this study, 60 OSCC and dysplastic oral epithelium samples were obtained from the Mashhad University of Medical Sciences together with their demographic and clinicopathological documents. LAMP3 expression was measured by qPCR.

Results: LAMP3 expression was significantly greater in OSCC than in dysplasia samples $(\mathrm{P}=0.001)$, in grade III OSCC than in grades I and II, and also greater in advanced than in early OSCC disease stage $(\mathrm{P}=0.001)$.

Conclusions: The significantly greater LAMP3 expression in OSCC than in dysplastic epithelium indicates a role for $L A M P 3$ in carcinogenesis in oral mucosa. Our results suggest $L A M P 3$ may be useful as an anticancer target and/or to predict disease pathogenesis in OSCC patient's cells.
\end{abstract}

Keywords: Clinicopathological, Grade, Epithelial dysplasia, LAMP3, Stage, Squamous cell carcinoma.

\section{Introduction}

Oral squamous cell carcinoma (OSCC) is a major subcategory of head and neck squamous cell carcinomas and accounts for more than $90 \%$ of oral cavity cancers (1). Although some investigations found OSCC related to tobacco and alcohol consumption, it has also been found in patients who used neither (2). Recently, the number of new OSCC cases has increased annually worldwide (3), and its high incidence rate concurs with metastasis, high recurrence, and poor prognosis in advanced stages $(4,5)$. Utilizing the novel diagnostic methods related to molecular markers could provide earlier or faster OSCC patient prognoses. Lysosome-associated membrane protein 3 (LAMP3, CD208, DCLAMP), a member of the LAMP protein family, is considered a molecular marker of mature dendritic cells (MDCs) (6). Increased LAMP3 expression is associated with unfavorable prognosis in many cancers including esophageal squamous cell carcinoma (ESCC) (7), gastrointestinal stromal tumor (GIST) (8), breast cancers $(9,10)$, cervical cancer $(11)$, and head and neck squamous cell carcinomas (6). This marker is associated with induction and promotion of tumor migration and invasion $(12,13)$. A significant relationship was seen between LAMP3 expression and lymph node metastasis $(6,7)$. Consequently, LAMP3 expression may be a predictor of cancer patient survival (6). Investigations of $L A M P 3$ expression and its association with OSCC patients' clinical features and pathological characteristics are lacking; hence, we aimed to analyze $L A M P 3$ expression in

1: Department of Oral and Maxillofacial Pathology, School of Dentistry, Mashhad University of Medical Sciences, Mashhad, Iran.

2: Oral and Maxillofacial Diseases Research Center, Mashhad University of Medical Sciences, Mashhad, Iran.

3: Dental Research Center, Mashhad University of Medical Sciences, Mashhad, Iran.

*Corresponding author: Farnaz Mohajertehran; Tel: +9851 38441130; E-mail: mohajertf@mums.ac.ir.

Received: 2 Oct, 2020; Accepted: 19 Oct, 2020 
OSCC tissue samples and dysplastic epithelium by quantitative polymerase chain reaction (qPCR). Furthermore, the relationship between LAMP3 expression and OSCC patient demographic features and histological characteristics were assessed. Our results suggest $L A M P 3$ expression may be a treatment target in for OSCC patients.

\section{Materials and methods}

\section{Study participants and sample preparation}

This study was performed in the Oral and Maxillofacial Pathology Department of Mashhad Dental School, Mashhad University of Medical Science, from November 2016 to November 2019. Sixty specimens from 60 patients were obtained as paraffin blocks from the dentistry pathology archive. We recorded the patients' demographic characteristics including age, sex, and alcohol, smoking, and drug consumption. In addition, the tumor grades and stages were recorded.

Patients with OSCC who had received no treatment until the time of sampling, who had no previous radiotherapy or chemotherapy, and currently had no other skin or oral diseases were included. In addition, we included all paraffin block specimens with sufficient lesion volume for testing. All RNA samples to be used for qRTPCR were first analyzed for quality on a NanoDrop 1000 spectrophotometer (NanoDrop Technologies, Wilmington, Thermo, USA). Thereafter, cDNA was synthesized by standard procedure (Thermo Scientific Revert Aid First Strand cDNA Synthesis Kit, Thermo Scientific, USA). cDNA was synthesized in $20 \mu \mathrm{L}$ reactions containing $4 \mu \mathrm{L}$ of $5 \mathrm{x}$ reaction buffer, $1 \mu \mathrm{L}$ of RiboLock RNase inhibitor, $2 \mu \mathrm{L}$ of $10 \mathrm{mM}$ dNTP mix and $1 \mu \mathrm{L}$ of reverse transcriptase on an ABI thermocycler (One Step, USA). Only cDNA samples of sufficient quality for testing and samples that met required storage conditions were included in the study. Five-micron-thick tumor and dysplastic tissue sections were obtained, sterilized in microtubules, and transferred to the Mashhad Medical School Pathology Laboratory for $L A M P 3$ expression analyses.

\section{Quantitative Real-time PCR (qPCR)}

For qPCR, tumor and dysplastic tissue samples were placed in sterile micro-tubes containing RNAlater and stored at $-80{ }^{\circ} \mathrm{C}$. RNA was extracted using an RNeasy mini kit following the manufacturer's protocol (High Pure RNA Tissue Kit, Roche, Germany). After RNA extraction, LAMP3 cDNA was synthesized (Thermo Scientific RevertAid First Strand cDNA Synthesis Kit, Scientific Thermo, USA) in $20 \mu \mathrm{L}$ reactions containing $4 \mu \mathrm{L}$ of $5 \mathrm{x}$ reaction buffer, $1 \mu \mathrm{L}$ of RiboLock RNase inhibitor, $2 \mu \mathrm{L}$ of $10 \mathrm{mM}$ dNTP mix and $1 \mu \mathrm{L}$ of reverse transcriptase on an $\mathrm{ABI}$ thermocycler (One Step, USA). The quality and concentration of the cDNAs were determined on a NanoDrop 1000 spectrophotometer (NanoDrop Technologies, Wilmington, DE, USA).

qPCR was performed to quantitate the relative expression of LAMP3 using a SYBR Green master mix kit (Thermos Scientific, Germany) on an ABI thermocycler (One Step, USA) with appropriate primers (Table 1). All reactions were performed in duplicate in $20 \mu \mathrm{L}$ volumes in separate wells. Each reaction contained $0.5 \mu \mathrm{L}$ of each primer $(10 \mathrm{pM}), 10 \mu \mathrm{L}$ of SYBR Green master mix, $7 \mu \mathrm{L}$ of DEPC water, and $2 \mu \mathrm{L}$ (4 ng) of cDNA extract. The PCR program started with 1 cycle at $94{ }^{\circ} \mathrm{C}$ for $10 \mathrm{~min}$ followed by denaturation, annealing, and replication processes including amplification cycles, respectively, at $94{ }^{\circ} \mathrm{C}$ for $30 \mathrm{sec}, 60{ }^{\circ} \mathrm{C}$ for 30 sec, and $72{ }^{\circ} \mathrm{C}$ for $30 \mathrm{sec}$. The final amplification followed at $72{ }^{\circ} \mathrm{C}$ for $35 \mathrm{sec}$. Differential expression was analyzed by the $\Delta \Delta \mathrm{CT}$ method. The housekeeping GAPDH gene was used as the reference gene (Figs. 1 and 2). Fold change above 2 was regarded as over expression, and below 2 as low or no expression (14-16).

Table 1. $L A M P 3$ and GAPDH Primer Sequences

\begin{tabular}{ccc}
\hline \multicolumn{2}{c}{ Gene } & Sequence \\
\hline \multirow{2}{*}{ LAMP3 } & Forward & 5'-CCTTCAAGTGCGTGAGTGAA-3' \\
\cline { 2 - 3 } & Reverse & 5'-CCATAAGGCAGAGACCAACC-3' \\
\hline \multirow{2}{*}{ GAPDH } & Forward & 5'-CCCATCACCATCTTCCAGG-3' \\
\cline { 2 - 3 } & Reverse & 5'-CATCACGCCACAGTTTCCC-3' \\
\hline
\end{tabular}




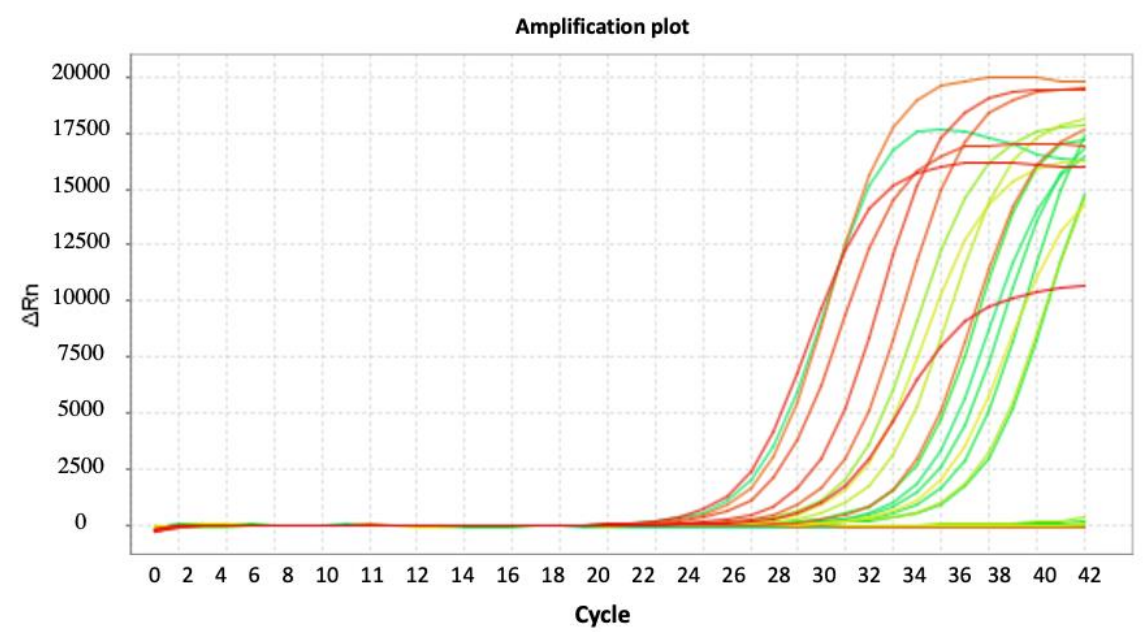

Fig. 1. Amplification plot for $L A M P 3$ and $G A P D H$ expression.

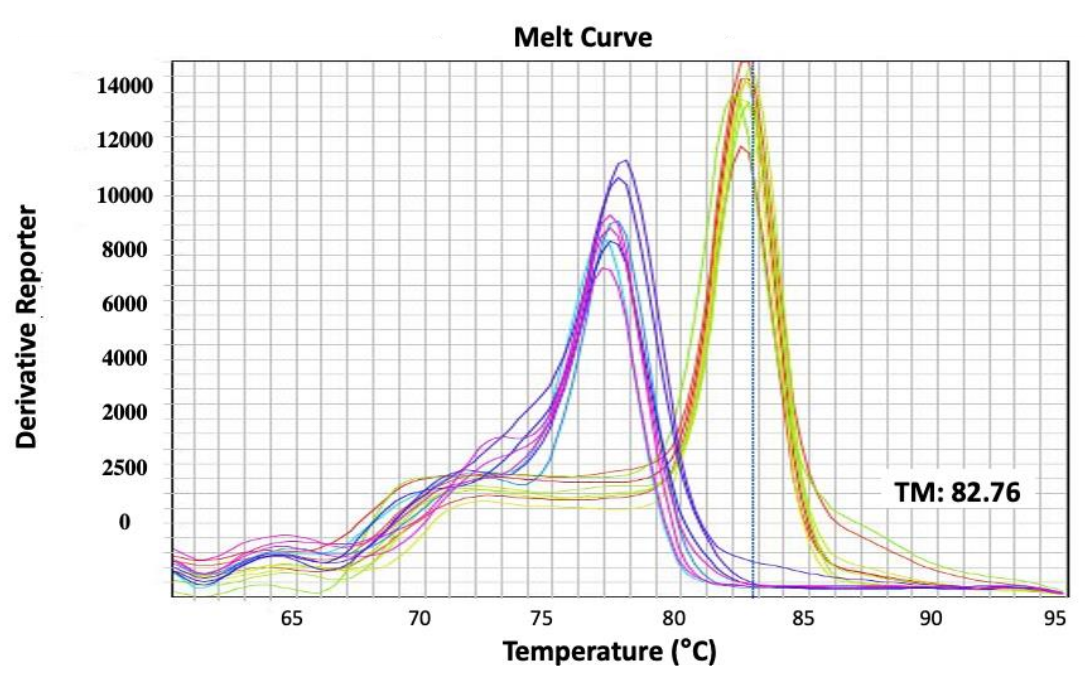

Fig. 2. Melt curve for $L A M P 3$ and GAPDH expression.

\section{Statistical Analyses}

Data were analyzed by SPSS software version 19.9 (SPSS Inc., Chicago, IL, USA). Descriptive data including age and $L A M P 3$ expression were summarized as means with the standard errors of means (SEMs). LAMP3 expression was compared in the tumoral and dysplastic tissues by the Mann-Whitney Test. LAMP3 expression in tumor and dysplastic tissues and its relationship with clinicopathological parameters, including tumor stage and histological grade, were evaluated by one-way ANOVA. The association between LAMP3 expression and demographic features between the dysplastic and OSCC groups were compared by independent sample $\mathrm{T}$ test. $\mathrm{P}$ values less than 0.05 were considered statistically significant.

\section{Results}

Study participant characteristics, and demographic and histologic features

The 60 patient samples included 15 OSCC grade I, 15 OSCC grade II, 15 OSCC grade III, and 15 dysplasia samples. Patients included 33 females and 27 males from 23 to 84 years old. Their demographic features are presented in Table 2. No statistically significant differences were found between the groups for age, gender, or smoke, alcohol, or drug consumption $(\mathrm{P}>0.05)$. Study participants included 20 cases $(44.4 \%)$ in early and 25 cases $(55.6 \%)$ in advanced OSCC stages.

\section{LAMP3 expression}

$L A M P 3$ expression was significantly greater in OSCC than in dysplasia patients. $(\mathrm{P}=0.001$; 
Table 3). LAMP3 expression was significantly greater in dysplasia tissue specimens from patients under 60 years of age than in those 60 years and older $(\mathrm{P}=0.01$; Table 4$)$; however, LAMP3 expression was not significantly different in OSCC samples from the two age groups $(\mathrm{P}=0.09)$. No significant difference in LAMP3 expression was seen between males and females in either the OSCC or dysplasia samples (P>0.05 for both, Table 4).

Table 2. Demographic information of study participants

\begin{tabular}{lllll}
\hline \multirow{2}{*}{ Variables } & & $\begin{array}{l}\text { Dysplastic tissue } \\
\text { Number (\%) }\end{array}$ & $\begin{array}{l}\text { Tumor tissue } \\
\text { Number (\%) }\end{array}$ & \multirow{2}{*}{ P value } \\
\hline \multirow{2}{*}{ Age } & $<60$ years & $7(46.7)$ & $30(66.7)$ & \multirow{2}{*}{0.14} \\
\hline \multirow{2}{*}{ Gender } & Female & $8(53.3)$ & $15(33.3)$ & \multirow{2}{*}{0.55} \\
\hline \multirow{2}{*}{ Smoking } & Male & $7(43.3)$ & $20(45.6)$ & \multirow{2}{*}{0.17} \\
\hline \multirow{2}{*}{ Alcohol } & No & $12(80)$ & $28(62.6)$ & \multirow{2}{*}{0.36} \\
\hline \multirow{2}{*}{ Drug } & No & $3(20)$ & $\begin{array}{l}17(37.8) \\
3(6.7)\end{array}$ & \multirow{2}{*}{0.27} \\
\hline
\end{tabular}

$* \mathrm{P}<0.05$ was considered significant.

Table 3. LAMP3 expression in OSCC and dysplasia specimens based on QRT analysis

\begin{tabular}{llll}
\hline Variables & $\begin{array}{l}\text { Dysplasia patients } \\
\text { Mean } \pm \text { SE }\end{array}$ & $\begin{array}{l}\text { OSCC patients } \\
\text { Mean } \pm \text { SE }\end{array}$ & P value \\
\hline LAMP3 Expression & $1.02 \pm 0.44$ & $7.99 \pm 4.31$ & $0.001^{*}(\mathrm{Z}=5.76)$ \\
\hline
\end{tabular}

* P value calculated by Mann-Whitney test. $\mathrm{P}<0.05$ was considered significant. SE; standard error of the mean, Squamous cell carcinoma of oral cavity (OSCC).

Table 4. Association of $L A M P 3$ expression with demographic characteristics between two study groups.

\begin{tabular}{|c|c|c|c|c|c|}
\hline Variables & & $\begin{array}{l}\text { Dysplasia tissue } \\
\text { Mean } \pm \text { SE }\end{array}$ & $P$ value & $\begin{array}{l}\text { Cancer tissue } \\
\text { Mean } \pm \text { SE }\end{array}$ & $P$ value \\
\hline Age & $\begin{array}{l}<60 \text { years } \\
\geq 60 \text { years }\end{array}$ & $\begin{array}{l}1.34 \pm 0.08 \\
0.85 \pm 0.14\end{array}$ & $0.01 *$ & $\begin{array}{l}8.87 \pm 0.91 \\
6.78 \pm 0.82\end{array}$ & 0.09 \\
\hline Gender & $\begin{array}{l}\text { Female } \\
\text { Male }\end{array}$ & $\begin{array}{l}0.91 \pm 0.14 \\
1.12 \pm 0.18\end{array}$ & 0.37 & $\begin{array}{l}7.48 \pm 0.72 \\
8.45 \pm 1.05\end{array}$ & 0.45 \\
\hline
\end{tabular}

*P value calculated based on Independent Sample T test. $\mathrm{P}<0.05$ was considered significant. SE; standard error of the mean.

$L A M P 3$ expression was significantly greater in OSCC grades 1, 2, and 3 than in the dysplasia group, and increased as the OSCC grade severity increased. The expression difference between OSCC grades 1 and 2 was not significant, however, the differences between grade 3 and grades 1 and 2 were significant. $(\mathrm{P}<0.05)$. Also, LAMP3 expression was significantly greater in both early and advanced OCSS stages than in dysplasia, and significantly greater in advanced than in early OCSS. ( $\mathrm{P}=0.01)$ (Table 5).

Table 5. Association of $L A M P 3$ expression with pathological characteristics

\begin{tabular}{llll}
\hline Variables & & $\begin{array}{l}\text { LAMP3 expression } \\
\text { Mean } \pm \text { SE }\end{array}$ & P value \\
\hline \multirow{3}{*}{ Grade } & Dysplasia & $1.02 \pm 0.44$ & \\
& I & $6.27 \pm 2.93$ & $0.001^{*}$ \\
& II & $5.48 \pm 1.20$ & \\
Stage & III & $12.24 \pm 4.38$ & \\
& Dysplasia & $1.02 \pm 0.44$ & $0.001^{*}$ \\
\hline
\end{tabular}

$* \overline{\mathrm{P} \text { value calculated based on one-way ANOVA. } \mathrm{P}<0.05 \text { was considered significant. }}$ SE: standard error of the mean 


\section{Discussion}

The role of lysosomes in homeostasis, cancer biology, and macromolecular degradation has been well studied (17). Throughout cancer progression or cell transformation, lysosomes move to different cellular locations and arrangement by release of enzymes (18). LAMPs are a family of glycosylated proteins that primarily associate with the lysosome membrane and are expressed at different levels in different tissues. An anticancer therapy role for LAMPs has been suggested for five members of this family including $L A M P 1, L A M P 2, L A M P 3$, CD68/macrosialin/LAMP4, and BAD$L A M P / L A M P 5$. It has been shown that cancer aggressiveness is increased by lysosomal release of LAMPs (19). LAMP3, located on a chromosome $3 \mathrm{q}$ segment, was initially isolated as a gene specifically expressed in lung. A role for $L A M P 3 \mathrm{e}$ was characterized in some human cancers including SCC and uterine and cervical cancers (11).

A previous study found a gain of $3 q$ in $90 \%$ of tumor tissue and only $7 \%$ in severe dysplasia of invasive cervical carcinomas. The authors suggested that a functionally important gene for cervical carcinogenesis might exist at 3q24-27. According to in cancers, this could be a suitable

\section{References}

1. Neville BW, Damm D, Allen C, Bouquot J. Salivary Gland Pathology. Oral and Maxillofacial Pathology. Elsevier, St. Louis; 2009.

2. Regezi JA, Sciubba J, Jordan RC. Oral pathology: clinical pathologic correlations: Elsevier Health Sciences; 2016.

3. Pektaș ZÖ, Keskin A, Günhan Ö, Karslioğlu Y. Evaluation of nuclear morphometry and DNA ploidy status for detection of malignant and premalignant oral lesions: quantitative cytologic assessment and review of methods for cytomorphometric measurements. Journal of oral and maxillofacial surgery. 2006;64(4):628-35.

4. Marshall JR, Graham S, Haughey BP, Shedd D, O'Shea R, Brasure J, et al. Smoking, alcohol, dentition and diet in the epidemiology of oral cancer. European Journal of Cancer Part B: Oral Oncology. 1992;28(1):9-15. candidate gene in previous investigation on altered $L A M P 3$ expression dysplastic and tumor tissues (20).

This present study investigated the expression of LAMP3 mRNA in grades 1-3 of oral SCC and in dysplasia. Due to limited studies and the importance of this marker in dysplasia and carcinomas, we compared dysplastic mucosa and OSCC in this study. Our results indicate a role for $L A M P 3$ and its increased expression in the process of oral mucosal carcinogenesis.

LAMP3 expression and patient age were inversely related in the dysplasia group; however, no significant difference in LAMP3 expression was seen between age groups with OSCC. Similar to our result,, Jun Lu et al. found no correlation between $L A M P 3$ expression in OSCC and patient age or gender $(6,21)$.

Our results indicate that $L A M P 3$ may be a relevant oncogene candidate potential prognosis factor in OSCC, and due to the many similarities, possibly other human cancers as well.

\section{Acknowledgements}

This project was supported by the Mashhad University of Medical Sciences of Iran (No. 970085).

5. Hindle I, Downer $\mathrm{M}$, Speight $\mathrm{P}$. The epidemiology of oral cancer. British Journal of Oral and Maxillofacial Surgery. 1996;34(5):471-6.

6. Lu J, Ma H, Lian S, Huang D, Lian M, Zhang Y, et al. Clinical significance and prognostic value of the expression of LAMP3 in oral squamous cell carcinoma. Disease markers. 2017;2017.

7. Liao X, Chen Y, Liu D, Li F, Li X, Jia W. High expression of LAMP3 is a novel biomarker of poor prognosis in patients with esophageal squamous cell carcinoma. International journal of molecular sciences. 2015;16(8):17655-67.

8. Zhao H, Zhu H, Jin Q, Zhang S, Wang W, Wang $\mathrm{D}$, et al. Association of high expression of Gro $\beta$ with clinical and pathological characteristics of unfavorable prognosis in gastrointestinal stromal tumors. Disease markers. 2015;2015. 
9. Nagelkerke A, Mujcic H, Bussink J, Wouters BG, van Laarhoven HW, Sweep FC, et al. Hypoxic regulation and prognostic value of LAMP3 expression in breast cancer. Cancer. 2011;117(16):3670-81.

10. Nagelkerke A, Sieuwerts AM, Bussink J, Sweep F, Look MP, Foekens JA, et al. LAMP3 is involved in tamoxifen resistance in breast cancer cells through the modulation of autophagy. Endocr Relat Cancer. 2014;21(1):101-12.

11. Kanao H, Enomoto T, Kimura T, Fujita M, Nakashima R, Ueda Y, et al. Overexpression of LAMP3/TSC403/DC-LAMP promotes metastasis in uterine cervical cancer. Cancer research. 2005;65(19):8640-5.

12. Nagelkerke A, Bussink J, Mujcic H, Wouters BG, Lehmann S, Sweep FC, et al. Hypoxia stimulates migration of breast cancer cells via the PERK/ATF4/LAMP3-arm of the unfolded protein response. Breast Cancer Research. 2013;15(1):R2.

13. Peltanova B, Raudenska M, Masarik M. Effect of tumor microenvironment on pathogenesis of the head and neck squamous cell carcinoma: a systematic review. Molecular cancer. 2019;18(1):63.

14. Mohtasham N, Ayatollahi H, Saghravanian N, Zare R, Shakeri M-T, Sahebkar A, et al. Evaluation of Tissue and Serum Expression Levels of Lactate Dehydrogenase Isoenzymes in Patients with Head and Neck Squamous Cell Carcinoma. Anti-Cancer Agents in Medicinal Chemistry (Formerly Current Medicinal Chemistry-Anti-Cancer Agents).
2019;19(17):2072-8.

15. Mohajertehran F, Ayatollahi H, Jafarian AH, Khazaeni K, Soukhtanloo M, Shakeri M-T, et al. Overexpression of lactate dehydrogenase in the saliva and tissues of patients with head and neck squamous cell carcinoma. Reports of biochemistry \& molecular biology. 2019;7(2):142.

16. Mohajertehran F, Ayatollahi H, Khazaeni K, Shakeri M-T, Mohtasham N. Overexpression of high-mobility motor box 1 in the blood and tissues of patients with head and neck squamous cell carcinoma. Iranian journal of otorhinolaryngology. 2018;30(100):261.

17. Fennelly C, Amaravadi RK. Lysosomal biology in cancer. Lysosomes: Springer; 2017. p. 293-308.

18. Pu J, Guardia CM, Keren-Kaplan T, Bonifacino JS. Mechanisms and functions of lysosome positioning. Journal of cell science. 2016;129(23):4329-39.

19. Alessandrini F, Pezzè L, Ciribilli Y, editors. LAMPs: Shedding light on cancer biology. Seminars in oncology; 2017: Elsevier.

20. Grade M, Difilippantonio MJ, Camps J. Patterns of chromosomal aberrations in solid tumors. Chromosomal instability in Cancer cells: Springer; 2015. p. 115-42.

21. Qiu X, You Y, Huang J, Wang X, Zhu H, Wang Z. LAMP3 and TP53 overexpression predicts poor outcome in laryngeal squamous cell carcinoma. International journal of clinical and experimental pathology. 2015;8(5):5519. 